\title{
Complex Morphology of Subducted Lithosphere in the Mantle below the Molucca Collision Zone from Non-linear Seismic Tomography
}

\author{
Sri Widiyantoro \\ Geodynamics Laboratory, Department of Geophysics and Meteorology \\ Faculty of Earth Sciences and Mineral Technology \\ Institut Teknologi Bandung, Indonesia
}

\begin{abstract}
Results of seismic studies presented in previous publications depict two opposing subducted oceanic lithospheric slabs under the Molucca region. This unique structure is related to the arc-arc collision between the Halmahera and Sangihe arcs. Recently, we have revisited the complex subduction zone structure by employing a non-linear tomographic imaging technique in which 3-D ray tracing has been implemented. We have used $\mathrm{P}$ - as well as S-wave arrival times from carefully reprocessed global data set. The results provide some improvements in the positioning of wave-speed anomalies.

Consistent with earlier results, the new P-wave model depicts the two opposing subducted slabs of the Molucca Sea plate. The intriguing new observation is that the westward dipping slab appears to penetrate into the lower mantle by taking the form of folded slab. We envisage that the folding behavior may have been caused by the shift of the whole subduction system in the Molucca region toward the Eurasian continent due to the westward thrust of the Pacific plate combined with the large left-lateral movement of the Sorong fault. The inversion of traveltime residuals of direct $\mathrm{S}$ phases strongly confirms the new observation.
\end{abstract}

Keywords: Molucca; non-linear seismic tomography; $P$ and $S$ waves; slab folding.

\section{$1 \quad$ Introduction}

The tectonic setting of the Molucca region in the eastern part of Indonesia has been marked by the arc-arc collision between the Halmahera arc to the east of the Molucca Collision Zone (MCZ) and the Sangihe arc to the west. The active collision between Halmahera and Sangihe is unique and represents the only known example of two colliding arcs in the world. The arc-arc collision has caused the two opposing subduction directions of the Molucca Sea plate, also known as the reversed U-shape structure (Hamilton, 1979; Cardwell et al., 1980; and Hall, 1987).

Given the complex tectonic process, it can be expected that the collision zone overlies a strongly heterogeneous mantle. Until the late 1990's investigations of mantle structure beneath the study region had mostly been based on seismicity, 
marine geophysical data, and volcanism. Therefore, lower mantle structure had not yet been revealed. Previous seismic tomograms of mantle structure below the region constructed by Puspito et al. (1993), Widiyantoro and Van der Hilst (1996 and 1997), and Bijwaard et al. (1998) provide evidence for slab penetration into the upper part of the lower-mantle of the westward down-going slab of the Molucca Sea plate. The tomographic images reveal a fast seismic wave-speed anomaly, which is detected to about $1,000 \mathrm{~km}$ in depth.

It is noted that all of the earlier tomographic works mentioned above were conducted by employing linearisations. The aim of this study is to revisit the subduction zone structure beneath the Indonesian region, in particular beneath the Molucca Collision Zone, by means of non-linear tomographic imaging. In this paper, we present vertical mantle cross sections through the new 3-D P-and S-wave tomographic models to show our new observation i.e. the folding of the westward subducted Molucca Sea plate in the lower mantle.

\section{$2 \quad$ Method}

Following Widiyantoro and Van der Hilst (1997) we have used a cellular representation of mantle structure by discretizing the entire mantle by means of local basis functions in the form of a uniform grid of constant velocity cells of $5^{\circ}$ by $5^{\circ}$, but in the study area we have used a relatively much finer grid of $0.5^{\circ}$ by $0.5^{\circ}$ in order to allow the resolution of relatively small-scale structure. We discretized the mantle volume under study, to a depth of $1,600 \mathrm{~km}$, into 19 layers with layer thickness ranging from $35 \mathrm{~km}$ in the uppermost layer to 200 $\mathrm{km}$ for the layer centered at $1,500 \mathrm{~km}$.

For stations and/or events located outside the mantle volume under study we combined ray paths from event to station clusters into a single ray, commonly referred to as the summary ray, in order to reduce the uneven sampling of mantle structure by ray paths and the dimension of the matrices involved in the inversions. For stations and events inside the study area, however, we used individual rays to optimize the sampling ( $c f$. Widiyantoro and Van der Hilst, 1996 and 1997).

In what follows we briefly present the aspects of the work which extend a nonlinear approach implemented through: (i) an application of 3-D ray tracing; and (ii) iterative inversion including re-ray tracing in updated 3-D models (note that in the previous works a one-step linear inversion procedure and 1-D ray tracing were employed). 


\subsection{Three-dimensional ray tracing}

The 3-D ray tracing algorithm used in this study is based on the pseudo-bending method for two-point ray tracing originally developed by Um and Thurber (1987). We have used the extension by Koketsu and Sekine (1998) to allow for propagation in a spherical Earth. The algorithm seeks direct minimisation of travel times to construct the propagation path with the endpoints at source and receiver fixed. This has a computational advantage over ray tracing techniques such as "shooting" based on Snell's law, which have only the source fixed (Widiyantoro et al., 2000).

\subsection{Three-dimensional model update}

Tomography for the seismic wave speed using arrival time information can be formulated as a non-linear inverse problem, which can then be solved by a sequence of linearisations about the current reference model ( $c f$. Nolet 1987). Each linearised stage requires the solution of a set of linear equations (see e.g. Widiyantoro et al., 2000). We have used the iterative LSQR method of Paige and Saunders (1982) i.e. a conjugate gradient technique which works directly with the linear equations. Nolet (1985) introduced this approach to handling the very large numbers of equations in seismic tomographic inversions and since then it has often been used.

The solution of the non-linear inverse problem for the 3-D wave-speed distribution thus contains a double iteration. The main iterative development is the progressive refinement of the slowness and event relocation vector commonly referred to as a 'global' iteration (Widiyantoro et al., 2000). We have preferred to force the event locations to be the essentially the same as those of Engdahl et al. (1998) by applying heavy damping in each of the global iterations. Notice that we are also working with S-wave data so we do not access to the most significant phases for earthquake location. Furthermore, as it is common in global as well as regional tomography, the relocation vectors have been calculated for event clusters (not for single earthquakes). For each of the global iterations we employed the iterative LSQR method and the iterative stages of the numerical solution of the linear equations are referred to as 'local' iterations. At each linearisation stage we have carried out 100 local iterations to make sure that the solution converges well, although in general the solution converges only after $\sim 25$ iterations. The global iteration of the linearised inversions converges much more rapidly than the local iterative solution of the linear equations.

The results of tests using synthetic data described in section 4 suggest that the pattern and amplitude of an input model are already largely recovered after one global iteration. From the first to the second global iteration, the heterogeneity 
becomes more spatially focused and an increase in the perturbation amplitude occurs. The model then becomes stable and changes are very small in subsequent global iterations. Following Widiyantoro et al. (2000) for this paper we present the inversion results of P- and S-wave information obtained after conducting three global iterations.

\section{$3 \quad$ Data}

For this study, we used travel-time residuals resulting from an updated global data set carefully reprocessed by Engdahl et al. (1998). This new data set covers the period 1964-1999 and has nearly 20\% more data that include nearly 100,000 global events recorded at a subset of about 7,000 seismographic stations worldwide. The distribution of events and stations inside the volume under the Indonesian region is shown in Fig. 1.

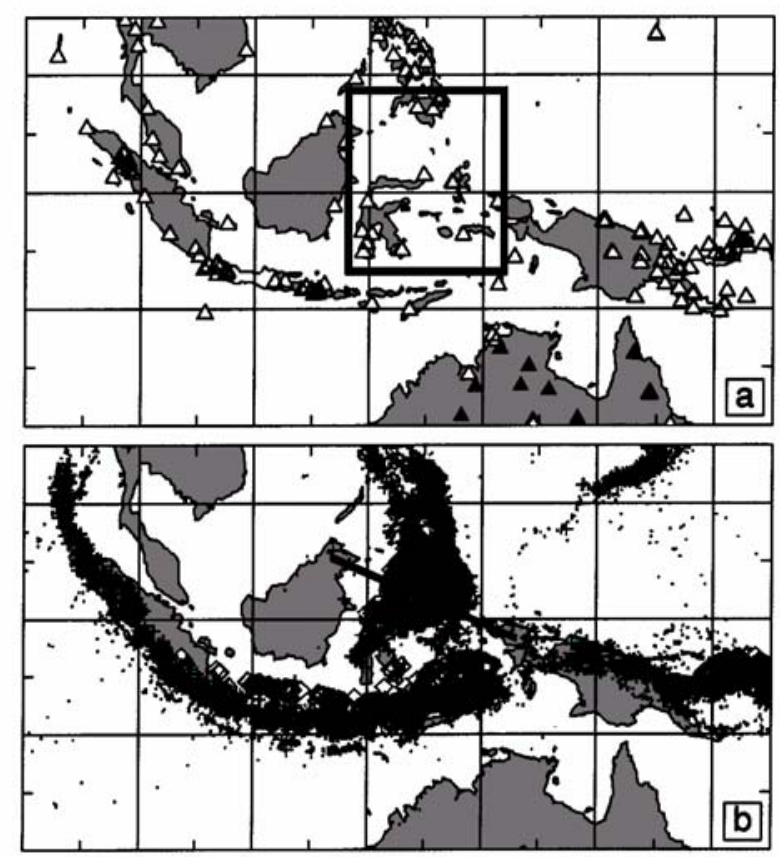

Figure 1 Distribution of seismographic stations and epicentres within the study area. (a) Station distribution including Skippy stations (solid triangles); see Van der Hilst et al. (1994). Rectangle depicts the focus of the region under investigation i.e. the Molucca Collision Zone (MCZ). (b) Epicentre distribution of earthquakes occurred between 1964 and 1999 in the Indonesian region. An updated version of event locations of Engdahl et al. (1998). Small dots, crosses and diamonds depict epicentres of shallow $(0<\mathrm{z} \leq 70 \mathrm{~km})$, intermediate $(70<\mathrm{z}$ $\leq 300 \mathrm{~km})$, and deep ( $\mathrm{z}>300 \mathrm{~km})$ events; $\mathrm{z}$ is the hypocentre depth. Thick line depicts the location of profiles shown in Figs. 2 and 3. 
Here, all epicentral distances are considered. We used more than $10^{7}$ for $\mathrm{P}$ and $10^{6}$ for $\mathrm{S}$ data in order to construct summary rays. For the inversion we only kept the summary rays for which the absolute travel-time residual has a magnitude less than $5.0 \mathrm{sec}$ and $15.0 \mathrm{sec}$ for $\mathrm{P}$ and $\mathrm{S}$ data, respectively. If both the source and receiver are located within the study region we used individual ray paths to optimize the sampling. The total number of paths and travel-time residuals for each type of waves constituting the linear system is nearly 550,000 . This number is more than twice of the total number of unknowns/ velocity cells i.e. 214,372 determined by the model parameterization described in the previous section.

\section{Three-Dimensional Resolution Tests}

In this section, tests using synthetic data generated by employing 3-D ray tracing are presented. We have conducted some checkerboard tests using different anomaly sizes. Here, we intentionally have used impulsive positive and negative anomalies in the input model (see Fig. 2) in order to detect more easily the directions in which there may be poor resolution or smearing ( $c f$. Spakman 1991). We traced rays using the 3-D ray tracing technique through the synthetic input 3-D checkerboard model and used the same data set as used in the real data inversion. The inversion procedure also followed the treatment for the real data i.e. starting from the 1-D model with three global iterations.

To investigate the way in which random errors, which may be contained in the reported phase data, are mapped into the inversion we also conducted test inversions by adding simulated data errors i.e. a Gaussian probability distribution with variance of $1.00 \mathrm{~s}^{2}$ for $\mathrm{P}$ with zero mean to the calculated travel-time residuals. Notice that these resolution tests are unnecessarily complete, since we do not simulate accurately the effect of data errors and mislocation of earthquake hypocentres, and the test inversions are conducted using the same theoretical assumptions as employed in the inversion of real data. Therefore, we need to be cautious with the interpretation of the results of the tests. However, despite the shortcomings of the techniques employed to assess the images, the results of the resolution tests confirm that major observed structures in mantle regions well sampled by seismic rays are retrievable by the data used in the inversion. Slab structures underneath the Molucca Collision Zone can be recovered due to sufficient data coverage.

Fig. 2 depicts the result of the checkerboard test conducted by placing anomalies in even numbered layers and indicates that the good resolution is attained where the source and receiver distribution is favourable. The 3-D checkerboard test suggests that such large-scale anomalies are well resolved by 


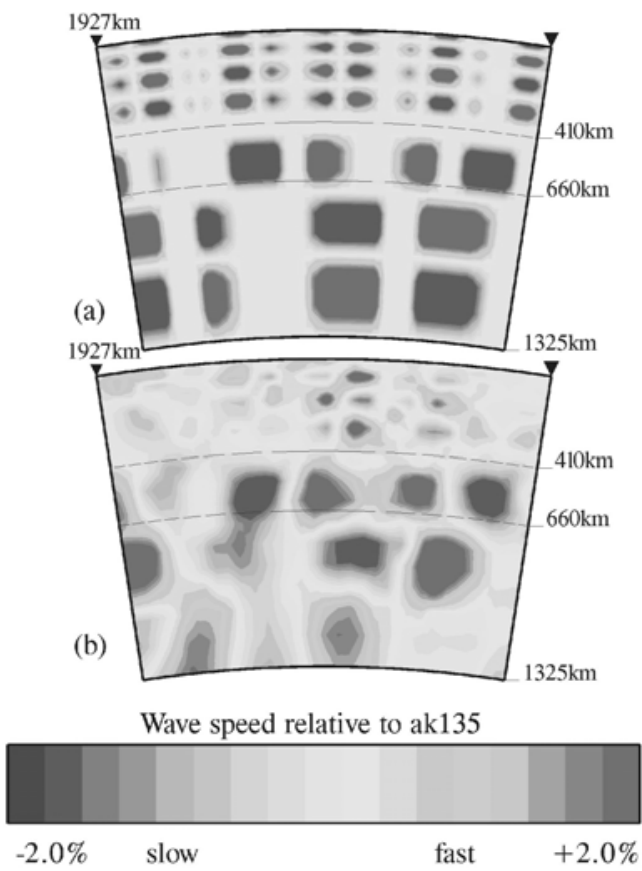

Figure 2 Results of checkerboard tests for tomograms given in Fig. 3. (a) Input model with $1.5^{\circ}$ by $1.5^{\circ}, 2.0^{\circ}$ by $2.0^{\circ}$ and $2.5^{\circ}$ by $2.5^{\circ}$ cellular velocity perturbations of $\pm 3.0 \%$ from the ak135 reference model in the upper mantle, transition zone and lower mantle, respectively. (b) The recovery achieved after conducting three global iterations using the same $\mathrm{P}$ data set and inversion procedure as employed in the inversion of real data. Contour scale: $-2.0 \%$ to $+2.0 \%$ relative to the reference velocity model (ak135). The length and depth of the cross section are $1927 \mathrm{~km}$ and $1325 \mathrm{~km}$, respectively.

the $\mathrm{P}$ data set. In particular, in the upper mantle and transition zone the dimension of the smallest feature that is about $150 \mathrm{~km}$ and $200 \mathrm{~km}$, respectively, is resolved. In the lower mantle the resolution length is of the order of about $250 \mathrm{~km}$ based on P- and S-wave imaging with comparable data coverage (Widiyantoro et al., in preparation). Notice that in the upper mantle resolution generally degrades with increasing distance away from the slab due to irregular or poor sampling. With this and the shortcomings of the resolution tests in mind, in what follows, we only discuss the large-scale structures.

\section{$5 \quad$ Discussion and Conclusions}

We discuss or interpret $\mathrm{P}$ and $\mathrm{S}$-wave travel-time residuals in terms of velocity perturbations relative to ak135 i.e. the radially stratified global reference 
velocity model developed by Kennett et al. (1995). Here, we present the images achieved after conducting 3 global iterations with 100 local iterations for each global iteration using the LSQR algorithm. The variance reduction upon inversion is about $75 \%$ and $60 \%$ for $\mathrm{P}$ and $\mathrm{S}$ data, respectively.

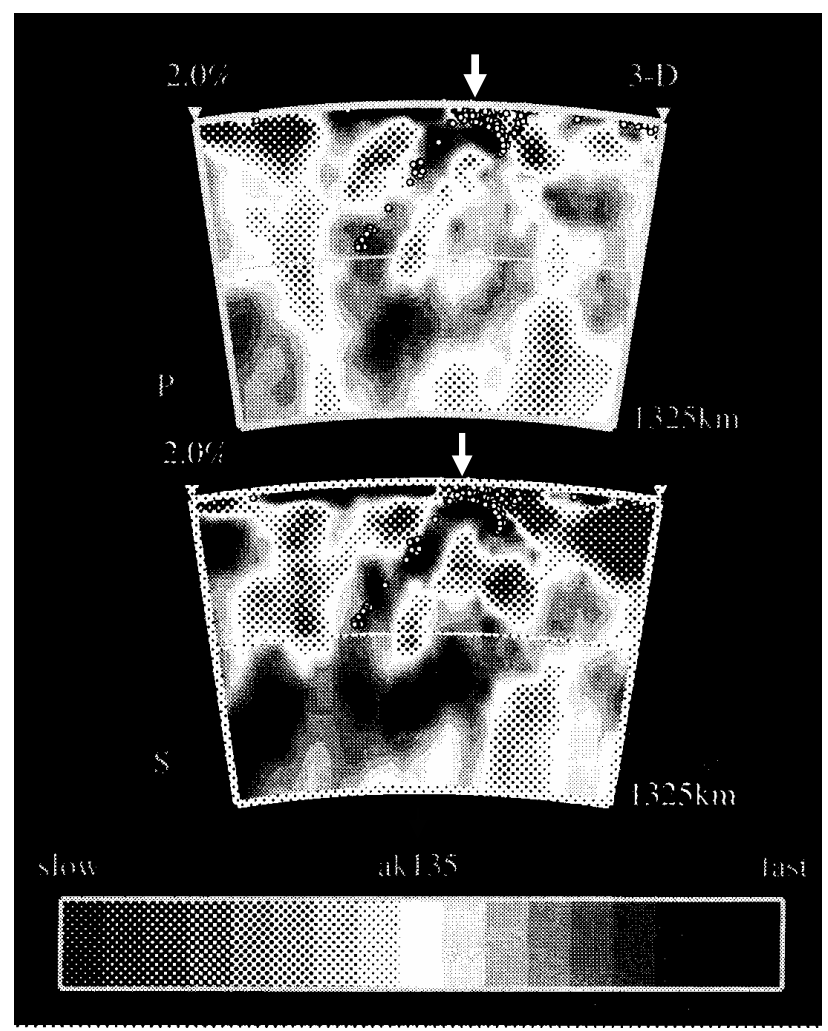

Figure 3 Results of tomographic inversions using the non-linear approach. Vertical mantle sections from the inversion of $\mathrm{P}$ data (Upper Panel) and $\mathrm{S}$ data (Lower Panel) plotted from northernmost Kalimantan (left) to the Bird's head of Papua (right) with contour scale $-2.0 \%$ to $+2.0 \%$ relative to the reference velocity model (ak135). Open dots depict earthquake hypocenters of magnitude $\geq 5.5$ on Richter's scale, projected from a distance of up to $0.5^{\circ}$ of both sides of the plane of the profile. Arrow indicates the center of the Molucca Collision Zone (Talaud Ridge). The length and depth of the cross section are $1927 \mathrm{~km}$ and $1325 \mathrm{~km}$, respectively.

P- and S-wave tomograms for mantle structure below the Molucca Collision Zone are shown in Fig. 3. From the inversions, we infer that the subducted slab is defined by a relatively continuous mantle region of higher-than-average Pand S-wave velocities in the mantle. Most parts of the region of interest, in 
particular along the subducted slabs, are well sampled by seismic rays and reasonably resolved by the P-wave data (Fig. 2).

The new P-wave tomographic image for mantle structure beneath the Molucca Collision Zone confirm the previously reported reversed U-shape structure associated with the two opposing subduction directions of the Molucca Sea plate, which have been related to the active arc-arc collision between Halmahera and Sangihe. In addition, the new seismic tomographic model reveals a new feature in which the westward subducted slab seems to penetrate into the lower mantle by taking the form of folded slab (Fig. 3a). Laboratory experiments suggest that such a folding of a subducted lithospheric slab is possible (GuillouFrottier et al., 1995). We argue that the folding behavior below the Molucca Collision Zone may have been caused by the westward shift of the whole Molucca subduction system owing to the westward thrust of the Pacific plate combined with the large left-lateral movement of the Sorong fault running eastwest to the south of the Molucca Sea through the Bird's head of Papua. These combined forces may have also caused the offset between the Philippine Sea

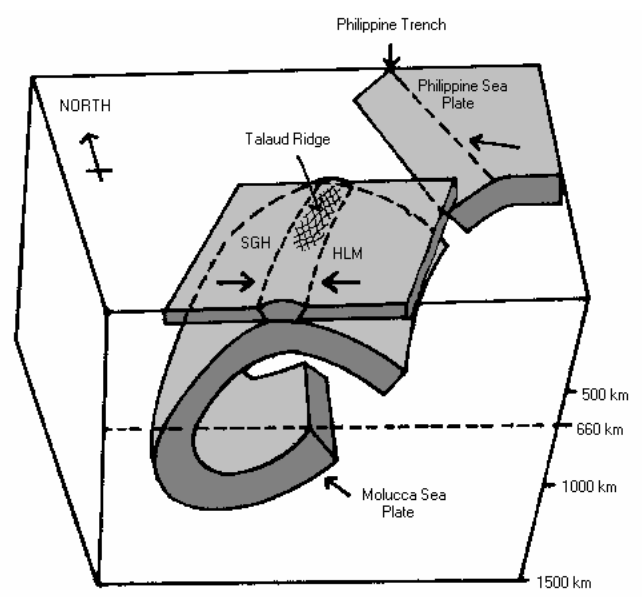

Figure 4 Configuration of the Molucca Sea and Philippine Sea plates [modified from Cardwell et al. (1980), and Widiyantoro and Van der Hilst (1997) based on the new tomographic images shown in Fig. 3]. An important modification is that the westward subduction of the Molucca Sea plate penetrates into the lower mantle by taking the form of folded slab. Abbreviations: SGH, Sangihe; and HLM, Halmahera.

and the Molucca Sea plate (Fig. 4); see also Widiyantoro and Van der Hilst (1997). Based on the new images we have refined the complex morphology of the subducted Molucca Sea plate into the structure depicted by the 3-D seismic 
cartoon shown in Fig. 4. The result of inversion of S-wave information is in an excellent agreement with the inference from $\mathrm{P}$ data (see Fig. 3b). This adds confidence to the interpretation on the folding of the westward dipping slab in the lower mantle.

In conclusion, the new seismic tomographic images reveal mantle structure beneath the Molucca Collision Zone in more detail than earlier studies thereby allowing the new observation described above. The improvements are likely to be due to the combination of the application of the non-linear approach, finer cells for parameterization and the use of more data. The results of 3-D resolution tests suggest that the large-scale slab structure is resolved by both $\mathrm{P}$ and $\mathrm{S}$ data. In spite of relatively noisy data, the results of $\mathrm{S}$ data inversion are qualitatively in good agreement with those from $\mathrm{P}$ data. Owing to the application of the non-linear approach the images are more spatially more concentrated and wave- speed perturbations are higher than those resulting from linearisations ( $c f$. Widiyantoro and Van der Hilst, 1997).

\section{Acknowledgments}

We are grateful to E. R. Engdahl, R. D. van der Hilst and R. Bulland for the updated hypocentre and phase data set used in this study. This work was supported by the Ministry of State for Research and Technology, Republic of Indonesia through an RUT (Riset Unggulan Terpadu) VIII Program, 20002002.

\section{References}

1. Bijwaard, H., Spakman, W. \& Engdahl, E.R., Closing the gap between regional and global travel time tomography, J. geophys. Res. 103, 3005530078 (1998).

2. Cardwell, R. K., Isacks, B. L. \& Karig, D. E., The spatial distribution of earthquakes, focal mechanism solutions and plate boundaries in the Philippine and northeastern Indonesia Islands, Am. Geophys. Union, Geophys. Monogr. 23, 1-35 (1980).

3. Engdahl, E. R., van der Hilst, R. D. \& Buland, R., Global teleseismic earthquake relocation with improved travel times and procedures for depth determination, Bull. Seism. Soc. Am. 88, $722-743$ (1998).

4. Guillou-Frottier, L., Buttles, J. \& Olson, P., Laboratory experiments on the structure of subducted lithosphere, Earth Planet. Sci. Lett. 133, 19-34 (1995).

5. Hall, R., Plate boundary evolution in the Halmahera region, Indonesia, Tectonophysics 144, 337-352 (1987). 
6. Hamilton, W., Tectonics of the Indonesian region, U.S. Geol. Survey Prof. Paper 1078, 345 pp. (1979).

7. Kennett, B. L. N., Engdahl, E. R. \& Buland, R., Constraints on seismic velocities in the Earth from traveltimes, Geophys. J. Int. 122, 108-124 (1995).

8. Koketsu, K. \& Sekine, S., Pseudo-bending method for three-dimensional seismic ray tracing in a spherical Earth with discontinuities, Geophys. J. Int. 132, 339-346 (1998).

9. Nolet, G., Solving or resolving inadequate and noisy tomographic system, J. Comp. Phys. 61, 463-482 (1985).

10. Nolet, G., Seismic wave propagation and seismic tomography, in Seismic Tomography, pp. 1-23, ed. Nolet, G., Reidel, Dordrecht (1987).

11. Paige, C. C. \& Saunders, M. A., LSQR: an algorithm for sparse linear equations and sparse least squares, ACM Trans. Math. Soft. 8, 43-71 and 195-209 (1982).

12. Puspito, N. T., Yamanaka, Y., Miyatake, T., Shimazaki, K. \& Hirahara, $\mathrm{K} .$, Three-dimensional P-wave velocity structure beneath the Indonesian region, Tectonophysics 220, 175-192 (1993).

13. Spakman, W., Delay-time tomography of the upper mantle below Europe, the Mediterranean, and Asia Minor, Geophys. J. Int. 107, 309-332 (1991).

14. Um, J. \& Thurber, C., A fast algorithm for two-point seismic ray tracing, Bull. Seism. Soc. Am. 77, 972-986 (1987).

15. Van der Hilst, R. D., Kennett, B. L. N., Christie, D. \& Grant, J., Project Skippy explores the lithosphere and mantle beneath Australia, EOS Trans. Am. Geophys. Union 75, 177 and 180-181 (1994).

16. Widiyantoro, S. \& Van der Hilst, R. D., Structure and evolution of lithospheric slab beneath the Sunda arc, Indonesia, Science 271, 15661570 (1996).

17. Widiyantoro, S. \& Van der Hilst, R. D., Mantle structure beneath Indonesia inferred from high-resolution tomographic imaging, Geophys. J. Int. 130, 167-182 (1997).

18. Widiyantoro, S., Gorbatov, A., Kennett, B. L. N. \& Fukao, Y., Improving global shear-wave delay-time tomography using three-dimensional ray tracing and iterative inversion, Geophys. J. Int. 141, 747-758 (2000).

19. Widiyantoro, S., Fauzi, Winardhi, S. \& Wandono, Three-dimensional mantle compressional and shear structure beneath Indonesia from nonlinear seismic delay-time tomography, in preparation. 